\title{
Chaetocin induces caspase-dependent apoptosis in ovarian cancer cells via the generation of reactive oxygen species
}

\author{
ZHONGJUN LI ${ }^{1}$, LISHAN HUANG ${ }^{1}$, LI WEI ${ }^{1}$, ZHIYONG HOU $^{1}$, WEIBIAO YE ${ }^{2}$ and SURAN HUANG ${ }^{1}$ \\ Departments of ${ }^{1}$ Obstetrics and Gynecology and ${ }^{2}$ Pathology, Dongguan Affiliated Hospital of \\ Southern Medical University, Dongguan, Guangdong 523059, P.R. China
}

Received November 18, 2018; Accepted May 24, 2019

DOI: $10.3892 /$ ol.2019.10507

\begin{abstract}
Ovarian cancer (OC) is one of the most common types of cancer among women worldwide. The majority of patients with OC respond to current chemotherapy approaches initially; however, patients are likely to experience cancer recurrence and become resistant to the chemotherapy. Therefore, novel agents for the treatment of OC are urgently required. Chaetocin, a natural product isolated from Chaetomium fungi, has been reported to exhibit anticancer activity against various types of cancer; however, the pharmacological action and detailed mechanism underlying the effects of chaetocin on $\mathrm{OC}$ cells remain unclear. Therefore, the present study investigated the cytotoxic effects of chaetocin on OC cells. A Cell Counting kit-8 assay was used to study cell viability, a colony formation assay was used to assess cell proliferation, flow cytometry was used to detect apoptosis, cell cycle and reactive oxygen species (ROS) generation, and western blotting was used to determine the protein levels of poly (ADP-ribose) polymerase, caspase-3 and cleaved-caspase-3. The results demonstrated that chaetocin significantly decreased the viability of OC cells. Chaetocin inhibited the proliferation and induced $\mathrm{G}_{2} / \mathrm{M}$ phase arrest of the OVCAR-3 OC cell line. Additionally, chaetocin induced apoptotic cell death in OVCAR-3 cells via the caspase pathway. It was observed that chaetocin induced the accumulation of ROS in OVCAR-3 cells. Treatment with the ROS scavenger $\mathrm{N}$-acetyl-L-cysteine reversed the apoptotic effects and activation of the caspase pathway induced by chaetocin. Collectively, these results revealed that chaetocin suppressed the proliferation and promoted the caspase-dependent apoptosis of $\mathrm{OC}$
\end{abstract}

Correspondence to: Professor Suran Huang, Department of Obstetrics and Gynecology, Dongguan Affiliated Hospital of Southern Medical University, 3 Wangdao Road, Dongguan, Guangdong 523059, P.R. China

E-mail: suranhuangdg@163.com

Abbreviations: OC, ovarian cancer; ROS, reactive oxygen species; $\mathrm{NAC}, \mathrm{N}$-acetyl-L-cysteine; PI, propidium iodide

Key words: chaetocin, ovarian cancer, apoptosis, caspase, reactive oxygen species cells by increasing the levels of ROS. Therefore, chaetocin may serve as a potential therapeutic agent for the treatment of OC.

\section{Introduction}

Ovarian cancer (OC) is the eighth most common type of cancer and the eighth leading cause of cancer-associated mortality among women worldwide. A total of 295,414 women worldwide were reported to be diagnosed with OC in 2018; and 184,799 females succumbed from this gynecologic malignancy (1). The combination of surgery with chemotherapeutic agents based on platinum salts and taxanes is the main treatment approach for patients with advanced-stage OC. A total of $65-80 \%$ of patients with OC respond to chemotherapy initially; however, the majority of patients experience cancer recurrence and become resistant to chemotherapy (2). In addition, the 5-year survival of patients with advanced-stage OC is only $27 \%$ (3). Therefore, novel agents for OC treatment are urgently required.

Chaetocin is a natural product isolated from Chaetomium fungi, and possesses antibiotic properties and a thiodioxopiperazine structure $(4,5)$. Chaetocin has been reported to exhibit anticancer activity against various cancer cell lines, including hepatocellular carcinoma, glioma, myeloma, non-small cell lung cancer and leukemia cells (6-14). Isham et al (7) revealed that chaetocin exerts its antimyeloma activity by affecting oxidative stress. Additionally, chaetocin was reported to exhibit antihepatoma activity by dysregulating the splicing of hypoxia-inducible factor $1 \alpha$ pre-mRNA (11); however, the pharmacological effects and detailed mechanism of chaetocin against OC remain unclear. In the present study, the pharmacological effects of chaetocin on $\mathrm{OC}$ and the underlying mechanism were investigated.

\section{Materials and methods}

Reagents. Chaetocin and N-acetyl-L-cysteine (NAC) were obtained from Sigma-Aldrich (Merck KGaA, Darmstadt, Germany). z-VAD-fmk was purchased from Selleck Chemicals (Houston, TX, USA). Antibodies against poly (ADP-ribose) polymerase (PARP; 1:1,000; cat. no. 9532), caspase-3 (1:1,000; cat. no. 9662) and cleaved-caspase-3 (1:1,000; cat. no. 9661) were obtained from Cell Signaling 
Technology, Inc. (Danvers, MA, USA). Anti- $\beta$-actin (1:10,000; cat. no. 60008-1-Ig), and anti-mouse immunoglobulin G (1:5,000; cat. no. SA00001-1) and anti-rabbit immunoglobulin G (1:5,000; cat. no. SA00001-2) horseradish peroxidase-conjugated secondary antibodies were purchased from ProteinTech Group, Inc. (Chicago, IL, USA).

Cell culture. SKOV-3 (cat. no. ATCC HTB-77) and OVCAR-3 (cat. no. ATCC HTB-161) cells were obtained from the American Type Culture Collection (Manassas, VA, USA). KGN (cat. no. BNCC337610), A2780 (cat. no. BNCC341157) and IOSE80 (cat. no. BNCC340318) cells were obtained from BeNa Culture Collection (Beijing, China). All cell lines were cultured in RPMI-1640 (Thermo Fisher Scientific, Inc., Waltham, MA, USA), supplemented with $10 \%$ fetal bovine serum (Thermo Fisher Scientific, Inc.), $100 \mathrm{U} / \mathrm{ml}$ penicillin and $10 \mathrm{mg} / \mathrm{ml}$ streptomycin (Thermo Fisher Scientific, Inc.) in a humidified atmosphere with $5 \% \mathrm{CO}_{2}$ at $37^{\circ} \mathrm{C}$.

Cell viability assay. Cell viability was analyzed via a Cell Counting kit-8 (CCK8) assay (Nanjing KeyGen Biotech Co., Ltd., Nanjing, China). The OC cells were seeded in 96-well microplates $\left(1 \times 10^{4}\right.$ cells/well) and incubated at $37^{\circ} \mathrm{C}$ overnight. Following incubation with chaetocin $(0.05,0.1,0.25,0.5,0.75$, 1 and $2 \mu \mathrm{M})$ at $37^{\circ} \mathrm{C}$ for $24 \mathrm{~h}, 20 \mu \mathrm{l}$ of CCK 8 reagent was added into each well and incubated for another $4 \mathrm{~h}$. The absorbance was measured using a multimode reader at $450 \mathrm{~nm}$.

Colony formation assay. A total of 500 cells/well were seeded in a 6-well plate and incubated at $37^{\circ} \mathrm{C}$ overnight. The following day, the cells were treated with 2.5 and $5 \mathrm{nM}$ chaetocin and incubated for 9 days. The cells were then washed with PBS and fixed in ice-cold methanol for $10 \mathrm{~min}$ following treatment with chaetocin. The cells were then stained with crystal violet solution at room temperature for $10 \mathrm{~min}$ and washed with water. Images of the colonies were captured using an Epson Perfection V370 Photo scanner (Epson America, Inc., Long Beach, CA, USA).

Cell cycle analysis. The cells were treated with chaetocin $(0.5$ and $1 \mu \mathrm{M})$ for $12 \mathrm{~h}$. Following treatment, the cells were collected and fixed with $66 \%$ ice-cold ethanol at $4^{\circ} \mathrm{C}$ overnight, and then stained with $500 \mu 1$ propidium iodide (PI; BD Biosciences, Franklin Lakes, NJ, USA) at room temperature for $15 \mathrm{~min}$ in the dark. The cell cycle distribution was analyzed by flow cytometry $\left(\lambda_{\mathrm{ex}}=488 \mathrm{~nm}, \lambda_{\mathrm{em}}=630 \mathrm{~nm}, 10000\right.$ events analyzed).

Analysis of apoptosis. The chaetocin-induced apoptosis of OVCAR-3 cells was analyzed using an Annexin V-fluorescein isothiocyanate (FITC)/PI staining kit (Nanjing KeyGen Biotech Co., Ltd.). The cells were treated with various concentrations of chaetocin $(0.5,1$ and $2 \mu \mathrm{M})$ for $24 \mathrm{~h}$ and then washed with PBS. Subsequently, the cells were resuspended in a solution containing $500 \mu \mathrm{l}$ binding buffer, $5 \mu \mathrm{l}$ annexin V-FITC and $5 \mu \mathrm{l} \mathrm{PI}$ for $15 \mathrm{~min}$ at $37^{\circ} \mathrm{C}$ in the dark. The apoptotic cells were then analyzed by flow cytometry (for annexin V-FITC, $\lambda_{\mathrm{ex}}=488 \mathrm{~nm}, \lambda_{\mathrm{em}}=530 \mathrm{~nm}$; for PI, $\lambda_{\mathrm{ex}}=488 \mathrm{~nm}, \lambda_{\mathrm{em}}=630 \mathrm{~nm}$; 10000 events analyzed). Annexin $\mathrm{V}^{+}$and Annexin $\mathrm{V}^{+} / \mathrm{PI}^{+}$cells were determined as apoptotic cells.
Determination of intracellular reactive oxygen species (ROS). ROS generation was measured using a ROS assay kit (Beyotime Institute of Biotechnology, Shanghai, China). The cells were loaded with 2',7'-dichlorofluorescin diacetate $(10 \mu \mathrm{M})$ and incubated for $20 \mathrm{~min}$ at $37^{\circ} \mathrm{C}$ in the dark. Following this, the cells were treated with chaetocin for $1 \mathrm{~h}$ and washed with PBS. The fluorescence was measured by flow cytometry $\left(\lambda_{\mathrm{ex}}=488 \mathrm{~nm}, \lambda_{\mathrm{em}}=530 \mathrm{~nm}, 10000\right.$ events analyzed $)$.

Western blot analysis. The cells were treated with chaetocin and proteins were extracted using radioimmunoprecipitation assay buffer (Cell Signaling Technology, Inc.) containing protease and phosphatase inhibitors (Nanjing KeyGen Biotech Co., Ltd.). The concentration of proteins was determined with a BCA protein assay kit (Pierce; Thermo Fisher Scientific, Inc.); $50 \mu \mathrm{g}$ total cellular protein were separated by $10 \%$ SDS-PAGE (PARP, caspase- 3 and $\beta$-actin) or $15 \%$ SDS-PAGE (cleaved-caspase-3) and transferred onto polyvinylidene difluoride membranes. The membranes were then blocked in $5 \%$ non-fat dry milk and incubated with primary antibodies overnight at $4^{\circ} \mathrm{C}$. The following day, the membranes were incubated with the anti-mouse immunoglobulin $\mathrm{G}$ or anti-rabbit immunoglobulin $\mathrm{G}$ horseradish peroxidase-conjugated secondary antibodies at room temperature for $1 \mathrm{~h}$, and target proteins were detected using enhanced chemiluminescence. The gray values were analyzed using ImageJ software (version 1.52; National Institutes of Health, Bethesda, MD, USA).

Statistical analysis. All experiments were performed in triplicate, and data are presented as the mean \pm standard deviation. Statistical analysis was conducted via one-way analysis of variance followed by Tukey's post hoc test using GraphPad Prism software (version 6; GraphPad Software, Inc., La Jolla, CA, USA). $\mathrm{P}<0.05$ was considered to indicate a statistically significant difference.

\section{Results}

Chaetocin significantly reduces $O C$ cell viability. The present study determined the effects of chaetocin on OC cell viability. Various OC cell lines were treated with chaetocin $(0.05,0.1$, $0.25,0.5,0.75,1$ and $2 \mu \mathrm{M}$ ) for $24 \mathrm{~h}$, and the cell viability was then detected via a CCK8 assay. As presented in Fig. 1A-D, chaetocin significantly inhibited the viability of SKOV-3, OVCAR-3, KGN and A2780 cells in a dose-dependent manner, with half-maximal inhibitory concentrations of $0.30,60.66,81.86$ and $100.60 \mathrm{nM}$, respectively. In addition, the half-maximal inhibitory concentration of chaetocin in the IOSE80 normal ovarian surface epithelium cell line was $206.10 \mathrm{nM}$, (Fig. 1E), which was higher than the half-maximal inhibitory concentration of chaetocin in the OC cells (Fig. 1F).

Chaetocin inhibits the proliferation of $O C$ cells by inducing $G_{2} / M$ phase arrest. Colony formation assays were performed in the present study to determine the effects of chaetocin on the proliferation of OVCAR-3 cells. Chaetocin treatment at various concentrations resulted in fewer and smaller colonies of OVCAR-3 cells after 9 days (Fig. 2A). This suggested that chaetocin effectively inhibited the proliferation of OVCAR-3 cells. In addition, whether the reduced proliferation of 
A

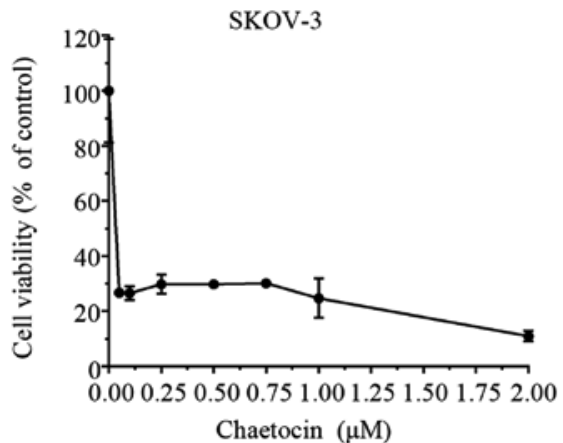

C

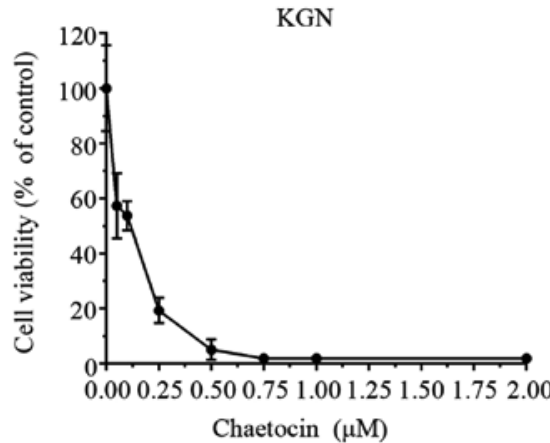

E

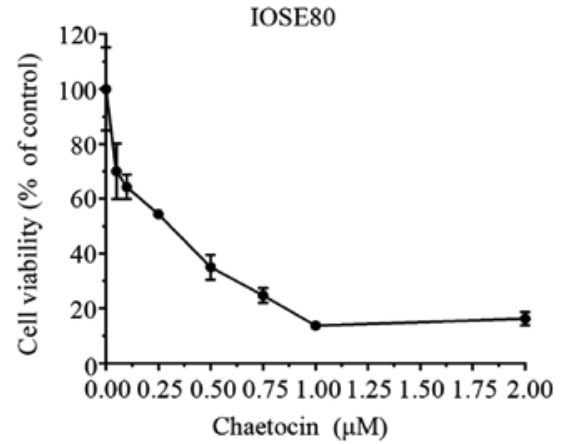

B

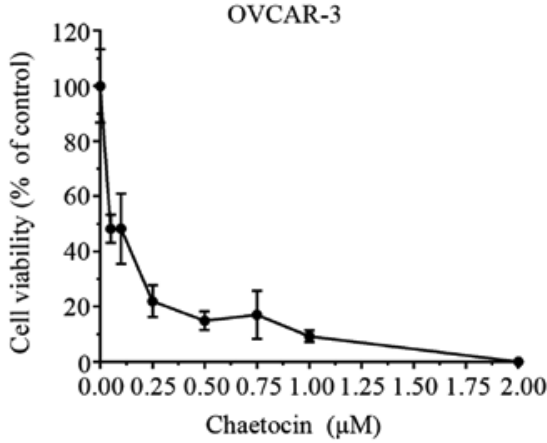

D

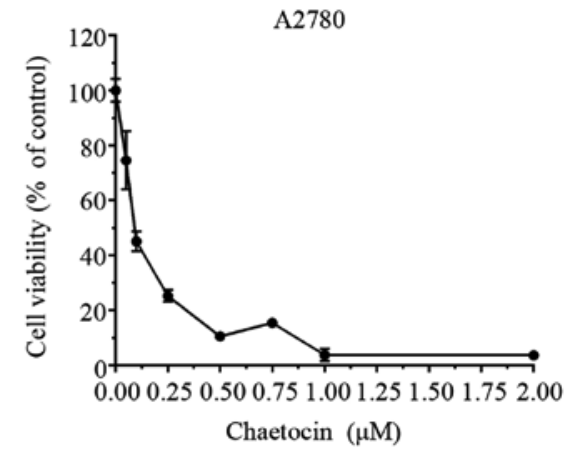

$\mathrm{F}$

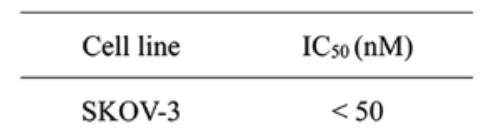

OVCAR-3 $60.66 \pm 15.56$

KGN $\quad 81.86 \pm 23.86$

$\mathrm{A} 2780 \quad 100.60 \pm 12.50$

IOSE80 $206.10 \pm 26.81$

Figure 1. Chaetocin significantly reduces OC cell viability. (A) SKOV-3, (B) OVCAR-3, (C) KGN, (D) A2780 and (E) IOSE80 cells were treated with various concentrations of chaetocin $(0.05,0.1,0.25,0.5,0.75,1$ and $2 \mu \mathrm{M})$ for $24 \mathrm{~h}$; cell viability was detected via a Cell Counting kit- 8 assay. $(\mathrm{F}) \mathrm{IC}_{50}$ values of chaetocin for each OC cell line and the normal ovarian surface epithelium cell line. OC, ovarian cancer; $\mathrm{IC}_{50}$, half-maximal inhibitory concentration.

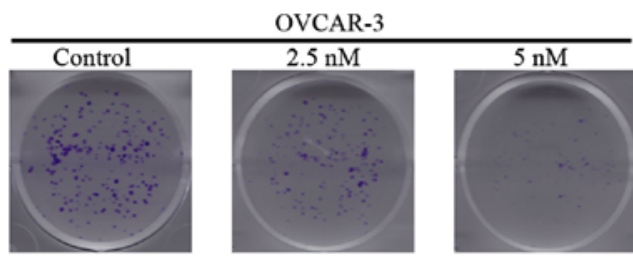

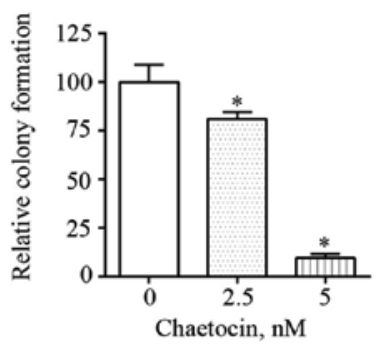

Chaetocin, $\mathrm{nM}$
B

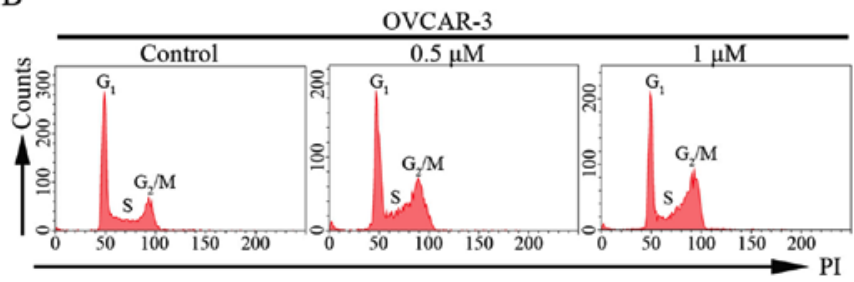

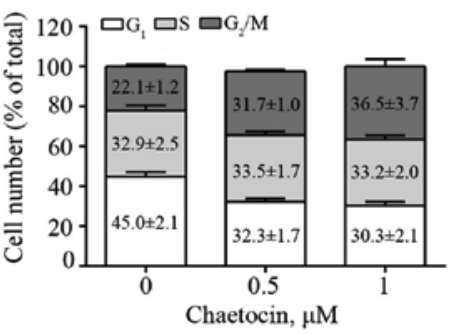

Figure 2. Chaetocin reduces proliferation and induces $\mathrm{G}_{2} / \mathrm{M}$ phase arrest in OVCAR-3 cells. (A) OVCAR-3 cells were treated with chaetocin for 9 days and the colony formation ability of the cells was then determined. "P $<0.05$ vs. control. (B) OVCAR-3 cells were treated with chaetocin for $12 \mathrm{~h}$ and the effects of chaetocin on the cell cycle distribution of OVCAR-3 cells were detected using flow cytometry. PI, propidium iodide. 
A
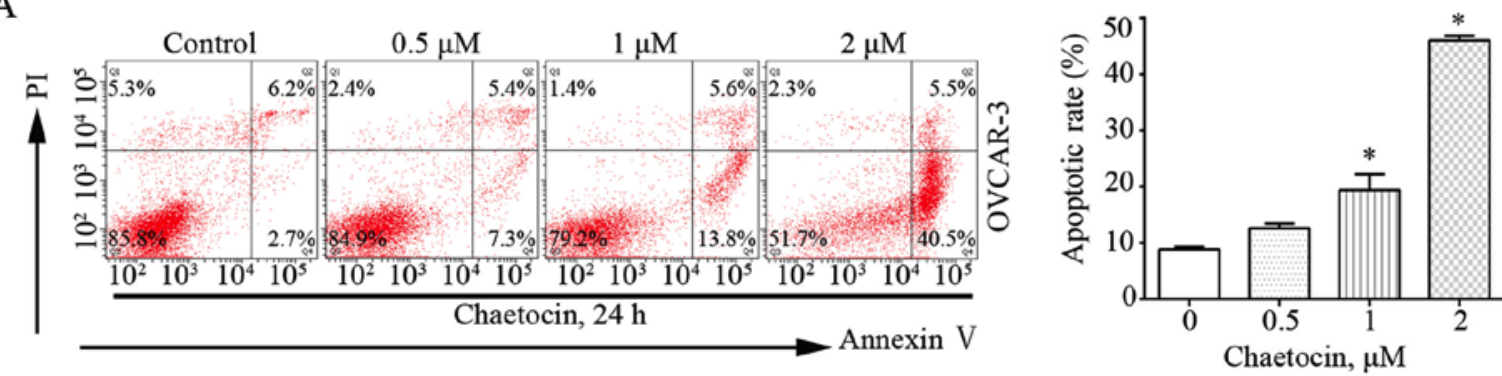

B
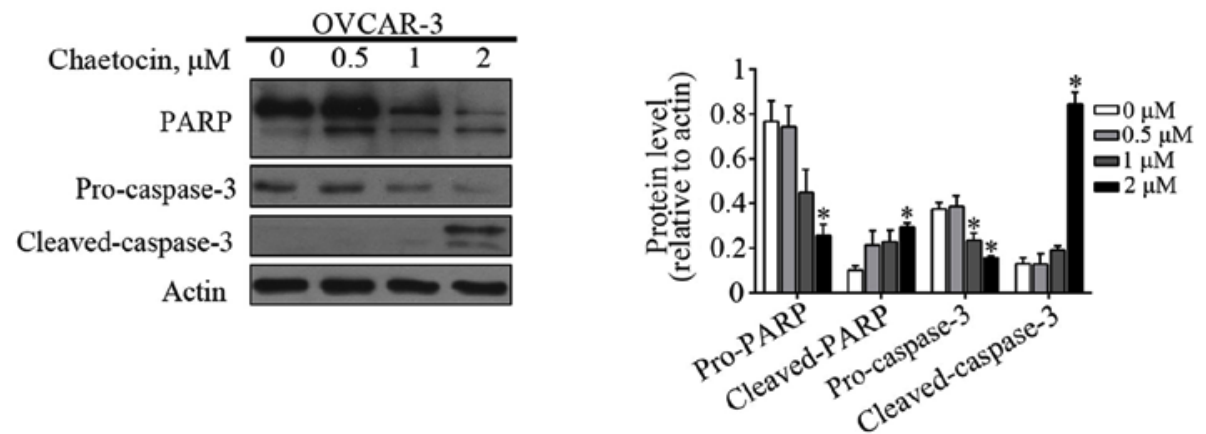

$\mathrm{C}$
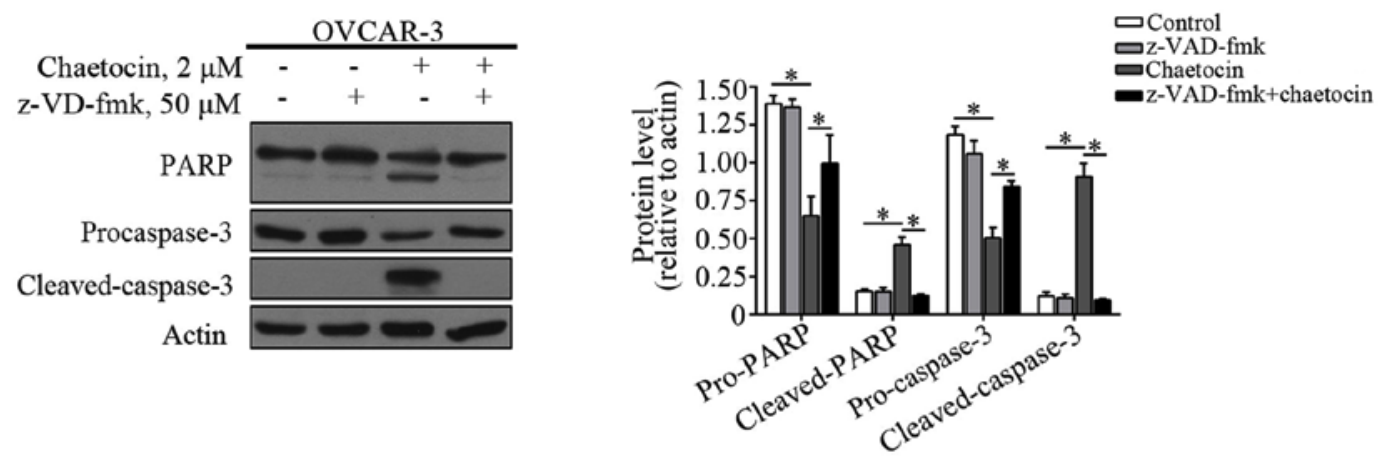

$\mathrm{D}$
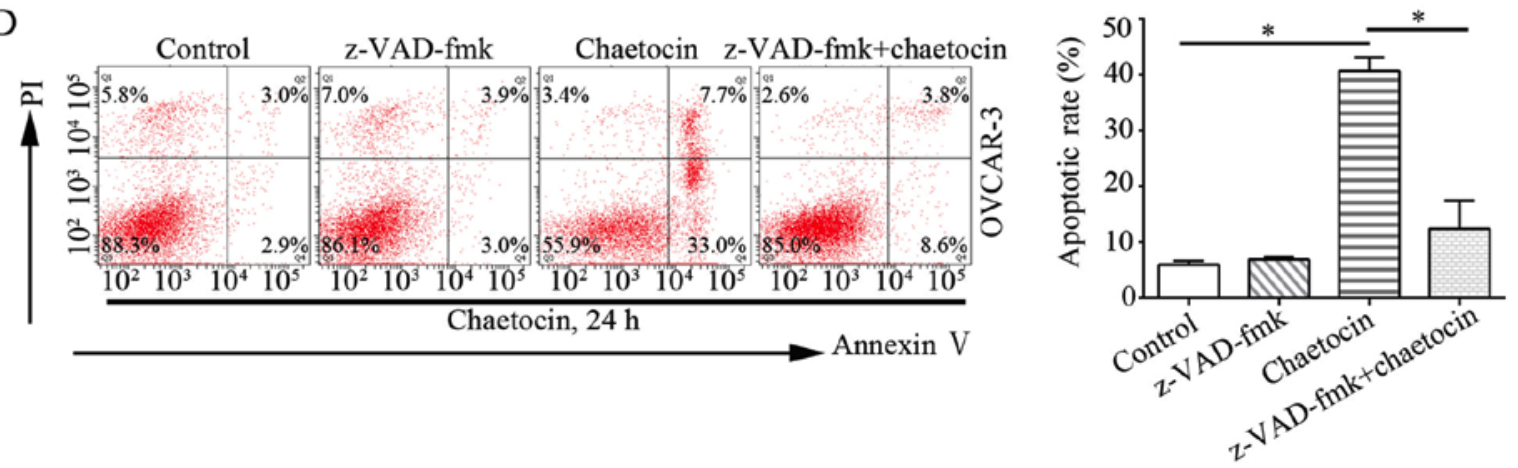

Figure 3. Chaetocin induces caspase-dependent apoptosis of OVCAR-3 cells. Cells were treated with various concentrations of chaetocin for 24 h. (A) Populations of apoptotic cells were determined by flow cytometry. ${ }^{\mathrm{P}}<0.05$ vs. control. (B) Expression levels of caspase- 3 and PARP were measured by western blot analysis. ${ }^{*} \mathrm{P}<0.05$ vs. control. Cells were treated with chaetocin for $24 \mathrm{~h}$, with or without $\mathrm{z}$-VAD-fmk. (C) Expression levels of caspase-3 and PARP were measured by western blot analysis. (D) Populations of apoptotic cells were determined by flow cytometry. ${ }^{*} \mathrm{P}<0.05$. PI, propidium iodide; PARP, poly (ADP-ribose) polymerase.

OVCAR-3 cells induced by chaetocin was associated with alterations in the cell cycle was investigated. The distribution of the cell cycle was analyzed by flow cytometry. Compared with that in the control group, the percentage of cells in the $\mathrm{G}_{2} / \mathrm{M}$ phase increased from $22.1 \%$ to 31.7 and $36.5 \%$ in OVCAR-3 cells treated with 0.5 and $1 \mu \mathrm{M}$ chaetocin for $12 \mathrm{~h}$, respectively (Fig. 2B). These results indicated that chaetocin inhibited the proliferation of $\mathrm{OC}$ cells by arresting the cell cycle at the $\mathrm{G}_{2} / \mathrm{M}$ phase.
Chaetocin induces the caspase-dependent apoptosis of $O C$ cells. Flow cy tometry was performed to analyze whether chaetocin induced the apoptosis of OVCAR-3 cells. As presented in Fig. 3A, chaetocin significantly increased the percentage of apoptotic OVCAR-3 cells, from $8.9 \%$ in the control group to 19.4 and $46.0 \%$ in the 1 and $2 \mu \mathrm{M}$ chaetocin treatment groups, respectively. This indicated that chaetocin induced apoptotic cell death in OC cells. In addition, apoptosis-associated proteins, including caspase- 3 and PARP, were affected by 
A
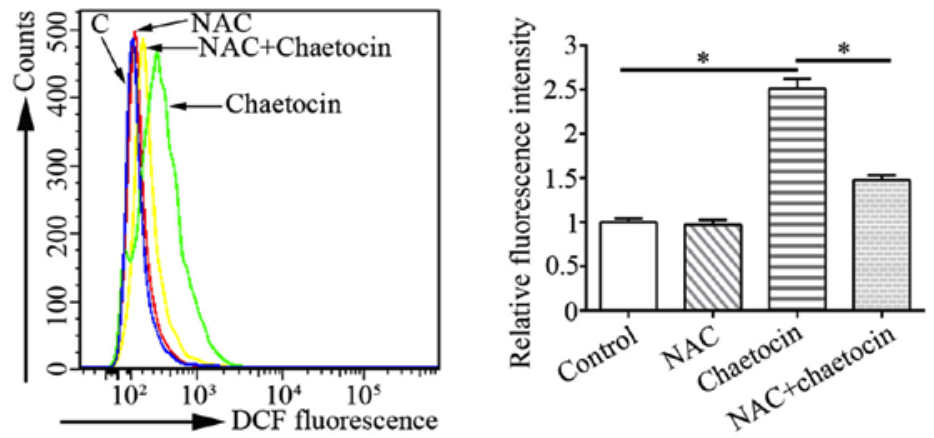

B
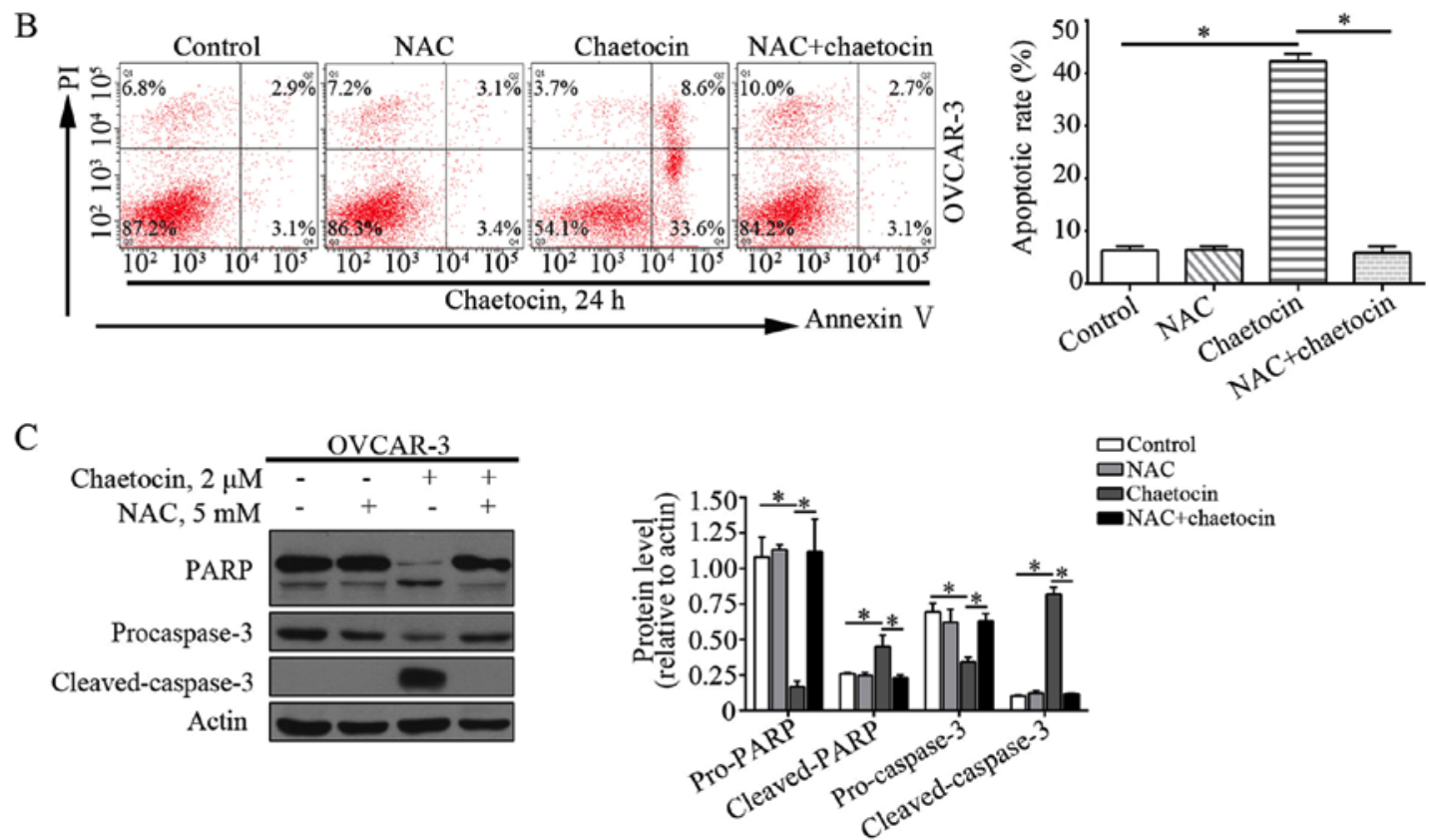

Figure 4. ROS production is crucial for chaetocin-induced caspase-dependent apoptosis for OVCAR-3 cells. (A) OVCAR-3 cells were treated with chaetocin for $1 \mathrm{~h}$, with or without NAC. Effects of chaetocin on ROS production were determined by flow cytometry. Cells were treated with chaetocin for $24 \mathrm{~h}$, with or without NAC. (B) Populations of apoptotic cells were determined by flow cytometry. (C) Expression levels of caspase-3 and PARP were measured by western blot analysis. ${ }^{*} \mathrm{P}<0.05$. ROS, reactive oxygen species; NAC, N-acetyl-L-cysteine; PI, propidium iodide; PARP, poly (ADP-ribose) polymerase.

chaetocin. Chaetocin decreased the expression levels of caspase-3 and PARP, but increased those of the cleaved forms of caspase-3 and PARP in OVCAR-3 cells (Fig. 3B). This further suggested that apoptosis was induced by chaetocin, which may occur via the caspase-dependent pathway. The pan-caspase inhibitor z-VAD-fmk was then used to validate whether the chaetocin-induced GC cell apoptosis depended on the caspase pathway. Of note, when OVCAR-3 cells were co-treated with chaetocin and z-VAD-fmk, the chaetocin-induced activation of the caspase pathway and resultant apoptosis were reduced (Fig. 3C and D). Collectively, these results suggested that chaetocin induced the caspase-dependent apoptosis of OC cells.

Chaetocin increases ROS accumulation in OC cells. ROS serve an essential role in cell proliferation and apoptosis. Previous studies have reported that chaetocin exerts the antimyeloma activity by affecting oxidative stress $(7,15)$. In addition, the effects of chaetocin on the levels of ROS in OVCAR-3 cells were determined. Compared with the control group, the levels of ROS were markedly increased in OVCAR-3 cells treated with chaetocin. This suggested that chaetocin induced ROS accumulation in OVCAR-3 cells (Fig. 4A).

ROS production is crucial for the chaetocin-induced caspase-dependent apoptosis of OC cells. The present study investigated whether ROS production mediated the anticancer activity of chaetocin against OVCAR-3 cells. The ROS scavenger NAC was used to inhibit the excessive ROS accumulation induced by chaetocin (Fig. 4A). When the cells were co-treated with chaetocin and NAC, the effects of chaetocin on the apoptosis of OVCAR-3 cells were notably abrogated (Fig. 4B). In addition, the cleavage of caspase-3 induced by chaetocin in OVCAR-3 cells was reversed (Fig. 4C). These data indicated that chaetocin-induced ROS accumulation may be associated with the caspase-dependent apoptosis of OVCAR-3 cells.

\section{Discussion}

$\mathrm{OC}$ is one of the most common types of gynecological cancer $(1,16)$. Carboplatin or cisplatin combined with paclitaxel 
is the standard treatment for patients with advanced-stage OC, however, the therapeutic effects are limited as the majority of patients experience cancer recurrence and become resistant to these anticancer agents $(2,3,17)$. Therefore, the development of novel effective agents against $\mathrm{OC}$ is required. In the present study, the therapeutic effects of chaetocin, a natural product isolated from Chaetomium fungi, were investigated in OC cells. Chaetocin induced cell cycle arrest of the OC cells in the $\mathrm{G}_{2} / \mathrm{M}$ phase and inhibited proliferation. Additionally, chaetocin caused the caspase-dependent apoptosis of OC cells. The levels of ROS were increased in OC cells following chaetocin treatment, which led to chaetocin-induced caspase-dependent apoptosis. The results of the present study suggest that chaetocin may be a potential therapeutic agent for the treatment of OC.

Apoptosis is a process of programmed cell death; several natural products have been reported to induce cancer cell death via apoptosis $(18,19)$. There are two major pro-apoptotic pathways: The death receptor-mediated extrinsic pathway and the mitochondrial-mediated intrinsic pathway, in which the caspase family of proteins serve a pivotal role in the process of programmed cell death. The extrinsic pathway activates caspase- 8 , while the intrinsic pathway activates caspase- 9 . These pathways activate caspase- 3 , which cleaves its substrate PARP and induces apoptosis (20,21). Han et al (15), reported that chaetocin exhibited pro-apoptotic effects on human melanoma cells via the intrinsic mitochondrial pathway. In acute myeloid leukemia cells, chaetocin induced apoptosis via the death receptor-mediated extrinsic pathway and mitochondrial-mediated intrinsic pathway (12). Similar to these studies, the results of the present study revealed that chaetocin induced the apoptosis of OC cells. Additionally, the caspase pathway was activated by chaetocin in OC cells; the pan-caspase inhibitor z-VAD-fmk reversed the apoptotic effects of chaetocin, suggesting that chaetocin induces the caspase-dependent apoptosis of OC cells.

ROS, comprising oxygen radicals and non-radicals, are a group of chemical molecules with high reactivity and important roles in cellular proliferation, differentiation and death (22-24). Excessive ROS accumulation can result in cell damage and death; cancer cells exhibit increased ROS levels compared with their normal counterparts (25-28). Therefore, developing ROS-targeting agents may be a potential strategy for the treatment of various types of cancer. In addition, numerous natural products have been reported to have notable anticancer activity by inducing ROS production. For example, piperlongumine, a natural alkaloid isolated from the fruit of long pepper, was observed to exhibit notable cytotoxic activity in numerous types of cancer by elevating ROS levels $(29,30)$. It has also been reported that chaetocin increases ROS levels and induces apoptosis in acute myeloid leukemia, myeloma and intrahepatic cholangiocarcinoma cells $(7,12,31)$. In the present study, elevated levels of ROS were detected in OVCAR-3 cells following chaetocin treatment. Of note, when chaetocin-induced excessive ROS production was inhibited by NAC, the chaetocin-induced apoptosis of OC cells was markedly abrogated. Additionally, the activation of caspases induced by chaetocin in OC cells was reversed. Collectively, these results indicated that chaetocin increased the production of ROS, which may be associated with the caspase-dependent apoptosis of OVCAR-3 cells induced by chaetocin.

In conclusion, the findings of the present study indicated that chaetocin suppressed the proliferation and induced the caspase-dependent apoptosis of OC cells via the excessive production of ROS. To the best of our knowledge, the present study is the first to investigate the detailed pharmacological effects of chaetocin on OC cells and the underlying mechanism. Therefore, chaetocin may be considered as a potential therapeutic agent in treating patients with OC; however, the effects of chaetocin in vivo and the molecular mechanism by which chaetocin affects OC cells require further investigation.

\section{Acknowledgements}

Not applicable.

\section{Funding}

The present study was financially supported by grants from the National Natural Science Foundation of China (grant no. 81702399), Guangdong Province Medical Scientific Research Foundation (grant nos. C2018053 and C2017034) and the National Medical Science and Technology Foundation (grant no. W2016CWGD05).

\section{Availability of data and materials}

The datasets used in the present study are available from the corresponding author upon reasonable request.

\section{Authors' contributions}

$\mathrm{SH}$ and $\mathrm{ZH}$ made substantial contributions to the conception of the present study and designed the experiments. ZL and WY performed the experiments and drafted the manuscript. LH and LW participated in data collection and analysis. All authors read and approved the final manuscript.

\section{Ethics approval and consent to participate}

Not applicable.

\section{Patient consent for publication}

Not applicable.

\section{Competing interests}

The authors declare that they have no competing interests.

\section{References}

1. Bray F, Ferlay J, Soerjomataram I, Siegel RL, Torre LA and Jemal A: Global cancer statistics 2018: GLOBOCAN estimates of incidence and mortality worldwide for 36 cancers in 185 countries. CA Cancer J Clin 68: 394,424, 2018.

2. Gamarra-Luques CD, Hapon MB, Goyeneche AA and Telleria CM: Resistance to cisplatin and paclitaxel does not affect the sensitivity of human ovarian cancer cells to antiprogestin-induced cytotoxicity. J Ovarian Res 7: 45, 2014. 
3. Cho KR and Shih IeM: Ovarian cancer. Annu Rev Pathol 4 287-313, 2009

4. Sekita S, Yoshihira K, Natori S, Udagawa S, Muroi T, Sugiyama Y, Kurata $\mathrm{H}$ and Umeda M: Mycotoxin production by Chaetomium spp. and related fungi. Can J Microbiol 27: 766-772, 1981.

5. Hauser D, Weber HP and Sigg HP: Isolation and configuration of Chaetocin. Helv Chim Acta 53: 1061-1073, 1970 (In German)

6. Liu X, Guo S, Liu X and Su L: Chaetocin induces endoplasmic reticulum stress response and leads to death receptor 5-dependent apoptosis in human non-small cell lung cancer cells Apoptosis 20: 1499-1507, 2015.

7. Isham CR, Tibodeau JD, Jin W, Xu R, Timm MM and Bible KC: Chaetocin: A promising new antimyeloma agent with in vitro and in vivo activity mediated via imposition of oxidative stress. Blood 109: 2579-2588, 2007.

8. Lai YS, Chen JY, Tsai HJ, Chen TY and Hung WC: The SUV39H1 inhibitor chaetocin induces differentiation and shows synergistic cytotoxicity with other epigenetic drugs in acute myeloid leukemia cells. Blood Cancer J 5: e313, 2015.

9. Isham CR, Tibodeau JD, Bossou AR, Merchan JR and Bible KC: The anticancer effects of chaetocin are independent of programmed cell death and hypoxia, and are associated with inhibition of endothelial cell proliferation. Br J Cancer 106 : 314-323, 2012.

10. Dixit D, Ghildiyal R, Anto NP and Sen E: Chaetocin-induced ROS-mediated apoptosis involves ATM-YAP1 axis and JNK-dependent inhibition of glucose metabolism. Cell Death Dis 5: e1212, 2014.

11. Lee YM, Lim JH, Yoon H, Chun YS and Park JW: Antihepatoma activity of chaetocin due to deregulated splicing of hypoxia-inducible factor $1 \alpha$ pre-mRNA in mice and in vitro. Hepatology 53: 171-180, 2011.

12. Chaib H, Nebbioso A, Prebet T, Castellano R, Garbit S, Restouin A, Vey N, Altucci L and Collette Y: Anti-leukemia activity of chaetocin via death receptor-dependent apoptosis and dual modulation of the histone methyl-transferase SUV39H1. Leukemia 26: 662-674, 2012.

13. Truitt L, Hutchinson C, DeCoteau JF and Geyer CR: Chaetocin antileukemia activity against chronic myelogenous leukemia cells is potentiated by bone marrow stromal factors and overcomes innate imatinib resistance. Oncogenesis 3: e122, 2014.

14. Vo MC, Nguyen-Pham TN, Lee HJ, Jung SH, Choi NR, Hoang MD, Kim HJ and Lee JJ: Chaetocin enhances dendritic cell function via the induction of heat shock protein and cancer testis antigens in myeloma cells. Oncotarget 8: 46047-46056, 2017.

15. Han X, Han Y, Zheng Y, Sun Q, Ma T, Zhang J and Xu L: Chaetocin induces apoptosis in human melanoma cells through the generation of reactive oxygen species and the intrinsic mitochondrial pathway, and exerts its anti-tumor activity in vivo. PLoS One 12: e175950, 2017.

16. Siegel RL, Miller KD and Jemal A: Cancer statistics, 2018. CA Cancer J Clin 68: 7-30, 2018.
17. Coleman RL, Monk BJ, Sood AK and Herzog TJ: Latest research and treatment of advanced-stage epithelial ovarian cancer. Nat Rev Clin Oncol 10: 211-224, 2013.

18. Wong RS: Apoptosis in cancer: From pathogenesis to treatment. J Exp Clin Cancer Res 30: 87, 2011.

19. Cotter TG: Apoptosis and cancer: The genesis of a research field. Nat Rev Cancer 9: 501-507, 2009.

20. Ferrin G, Linares CI and Muntané J: Mitochondrial drug targets in cell death and cancer. Curr Pharm Des 17: 2002-2016, 2011.

21. Dong Y, Cao A, Shi J, Yin P, Wang L, Ji G, Xie J and Wu D Tangeretin, a citrus polymethoxyflavonoid, induces apoptosis of human gastric cancer AGS cells through extrinsic and intrinsic signaling pathways. Oncol Rep 31: 1788-1794, 2014.

22. Roy J, Galano JM, Durand T, Le Guennec JY and Lee JC: Physiological role of reactive oxygen species as promoters of natural defenses. FASEB J 31: 3729-3745, 2017.

23. Holmström KM and Finkel T: Cellular mechanisms and physiological consequences of redox-dependent signalling. Nat Rev Mol Cell Biol 15: 411-421, 2014.

24. D'Autréaux B and Toledano MB: ROS as signalling molecules: Mechanisms that generate specificity in ROS homeostasis. Nat Rev Mol Cell Biol 8: 813-824, 2007.

25. Reuter S, Gupta SC, Chaturvedi MM and Aggarwal BB Oxidative stress, inflammation, and cancer: How are they linked? Free Radic Biol Med 49: 1603-1616, 2010.

26. Galadari S, Rahman A, Pallichankandy S and Thayyullathil F: Reactive oxygen species and cancer paradox: To promote or to suppress? Free Radic Biol Med 104: 144-164, 2017.

27. Weng MS, Chang JH, Hung WY, Yang YC and Chien MH: The interplay of reactive oxygen species and the epidermal growth factor receptor in tumor progression and drug resistance. J Exp Clin Cancer Res 37: 61, 2018.

28. Tafani M, Sansone L, Limana F, Arcangeli T, De Santis E, Polese M, Fini M and Russo MA: The interplay of reactive oxygen species, hypoxia, inflammation, and sirtuins in cancer initiation and progression. Oxid Med Cell Longev 2016: 3907147, 2016.

29. Zou P, Xia Y, Ji J, Chen W, Zhang J, Chen X, Rajamanickam V, Chen G, Wang Z, Chen L, et al: Piperlongumine as a direct TrxR1 inhibitor with suppressive activity against gastric cancer. Cancer Lett 375: 114-126, 2016.

30. Raj L, Ide T, Gurkar AU, Foley M, Schenone M, Li X, Tolliday NJ, Golub TR, Carr SA, Shamji AF, et al: Selective killing of cancer cells by a small molecule targeting the stress response to ROS. Nature 475: 231-234, 2011.

31. He J, Chen X, Li B, Zhou W, Xiao J, He K, Zhang J and Xiang G: Chaetocin induces cell cycle arrest and apoptosis by regulating the ROS-mediated ASK-1/JNK signaling pathways. Oncol Rep 38: 2489-2497, 2017.

This work is licensed under a Creative Commons Attribution-NonCommercial-NoDerivatives 4.0 International (CC BY-NC-ND 4.0) License. 